\title{
CAREER GUIDANCE AS A SUPPORTING TOOL FOR VOCATIONAL EDUCATION IN GEORGIA
}

\author{
Tinatin Sabauri \\ Ivane Javakhishvili Tbilisi State University, GEORGIA, email: tinatinsabauri@yahoo.de
}

\begin{abstract}
The article discusses the importance of career guidance and career planning and emphasizes the importance of professional orientation as a main mechanism in career planning.

The article gives an overview of the project "The school as a place of learning a profession" implemented within the framework of Vocational Training and Partnership in the South Caucasus Bildungswerk der Wirtschaft Mecklenburg Vorpommern e.V. funded by the German Federal Ministry of Education and Research (BMZ). Within the scope of the project four private schools were selected in Georgia. Secondary students from these schools visited various companies in Georgia.

Professional orientation and career planning consist of services that help students and beneficiaries successfully identify their strengths and weaknesses, interest areas and needs and go through externship in relevant areas.

The author of the article emphasizes the importance of the project "The school as a place of learning a profession" for the development of self-esteem, personal formation and informed career choice in young people. The project aims at implementing and developing career guidance in a pilot region. It will facilitate approximation and harmonization of Georgian vocational education to the European system.

As the results of the survey have shown, it is important to prepare students prior to their visits to companies, to increase their awareness on the features and characteristics of the profiling enterprise and give them information about the companies' activities, which will be unconditionally useful for practical teaching and job testing.
\end{abstract}

Keywords: Professional education, Students, Career Choices

"It is not the strongest of the species that survives, nor the most intelligent that survives.

It is the one that is most adaptable to change"

Charles Darwin

\section{INTRODUCTION}

Professional orientation and career planning consist of services that help students and beneficiaries successfully identify their strengths and weaknesses, interest areas and needs and go through externship in 
relevant areas.

One of the main components of professional orientation and career planning is a career consultation (individual and group) aiming at helping students to realize their work identity, define their lack of competencies (if any).

Professional orientation should be available for middle and secondary-level students, vocational/tertiary students before, during and at the end of their studies, while searching for a new job. It should facilitate an informed decision by students, reduction of learning abandonment, satisfaction with professional choice, effective financing, employment, etc.

\section{MAIN PART}

In November 2016 first time in the history of Georgia, a project "The school as a place of learning a profession" was implemented within the framework of Vocational Training and Partnership in the South Caucasus funded by the German Federal Ministry of Education and Research (BMZ). Within the framework of the project four private schools were selected in a pilot region of Georgia. Secondary-level students of these schools went through externship /externship in various companies such as: hypermarket "Goodwill", restaurants, a juice processing plant. The students were assigned to certain employees of the companies and carried out instructions. It is noteworthy that during the internship each company had appointed teams (consisting of 3-10 workers) supervising and instructing students while their externship.

The first day of the visit, called "Doors Open Day", was mainly limited to the question-answer mode, which was used to select the job positions the following day. The second day was devoted to "Job shadowing" and the students were given the chance to watch employees in the working process and learn new aspects related to the job, organization and competencies.

The students were especially interested in an "Externship day" when they were actually involved in working process. This day was more fun than the previous one when students had just to do job shadowing and watch employees. It is also interesting how students perceived "gendered jobs". For example, in a restaurant girls were more interested in "jobs for men". It should be emphasized that students were assigned to all units of the restaurant and once in every 3 hours they rotated and swapped positions. This enabled students to learn more about all positions.

It is noteworthy that, as the companies mentioned, this was the first time they had been visited by pupils and this experience was exceptional and novel with its practical load and duration. As managers of the companies say, it would be good to prepare and train their personnel for externship in the future.

Let us look at the results of each day of externship in various organizations according to activities offered on all three days:

The first day of the visit was "Doors Open Day" during which the secondary-level students visited various companies and received general information about the companies, their business and activities. At the end of the day all the students filled in an evaluation form \#1. Answers to open-end questions were the following:

The boys are interested in getting more detailed information about the company. Most of them want to be involved in the working process. They would like to be informed about how to be successful in their positions and have the opportunity to see the working process; they suggest that the externship and similar visits be implement throughout the country; most of them agree that they would like to try activities themselves than just shadow employees.

Boys suggested: "Before visiting a certain company, it would be better to organize a meeting in order to share our expectations, exchange ideas about company's activities and business;" "I would have planned the factory tour in a more detailed way to let the visitors see things being manufactured".

Girls advised companies to "create a friendly atmosphere for the tour". They want to be involved in several days of practice; they see the need to involve more young people in the project; The girls believe that it would be better to receive information about the activities of companies before visiting them; Girls want to be given an opportunity to try themselves in various positions in companies, which will help them identify their skills, strengths and priorities.

During the second day devoted to the "Job shadowing" the students had an opportunity to watch employees in the working process. This could help them identify occupations and directions interesting to them. At the end of the day they received a satisfaction form \#2 which they confidentially filled in, as usual.

As for the students' satisfaction and suggestions, almost all of them wants to be actually involved in the working process. "It would be better to choose a company where we will be able to participate in the working 
process. We should vote to decide which company to visit". They wish to have an environment (correspondingly grouping of students) ensuring better receipt of information. Teachers' priority is to ensure and increase parents' involvement in the project.

The third day of externship was devoted to the module of "Externship day" during which students did a oneday externship. Most of the boys are satisfied with the externship day. They wish for more practice and more insight into what they can expect to experience within the field they have chosen. As for girls' suggestions, they turned out to be more creative and, demanding:

"Let's carry out the project according to professions we want in order to do have a practical look at their chosen career field."; "The distribution of students to positions should be more organized", "I would give students an opportunity to do externship only with their supervisors, without parents' and teachers' observation.

After the three days long externship, within the frames of the project, an event "Business with us" was held. Participants met successful business managers in Gori and gave presentations about the tours, "jobshadowing" and externship days they did during the project. The aim of the event was to gain a closer insight into the students' impressions. In their turn, representatives of companies spoke about their success stories and aspects of convergence of corporate interests. The meeting continued in the discussion format. At the end of the meeting, effective steps to integrate youth labor market were jointly defined for 2017.

At the final stage of the meeting participants were given questionnaires (satisfaction evaluation form Nr. 4), they gave following answers to the open question: "what do you suggest to make meetings with representatives of business and company's management more interesting and more promising": the majority of boys wish the environment to be more friendly than business-like and to be informed beforehand about future meeting.

Girls were satisfied with planned activities but wished to visit the organizations once again and have an opportunity to test their skills.

As for teachers'/parents' priorities, they want business representatives to assign students to certain positions for a few days in their organizations so that students will gain valuable experience for their future careers. They ask this project to "involve as many industrial and construction companies as possible"; "to make this type of meetings and activities more systematic" and "ensure community involvement".

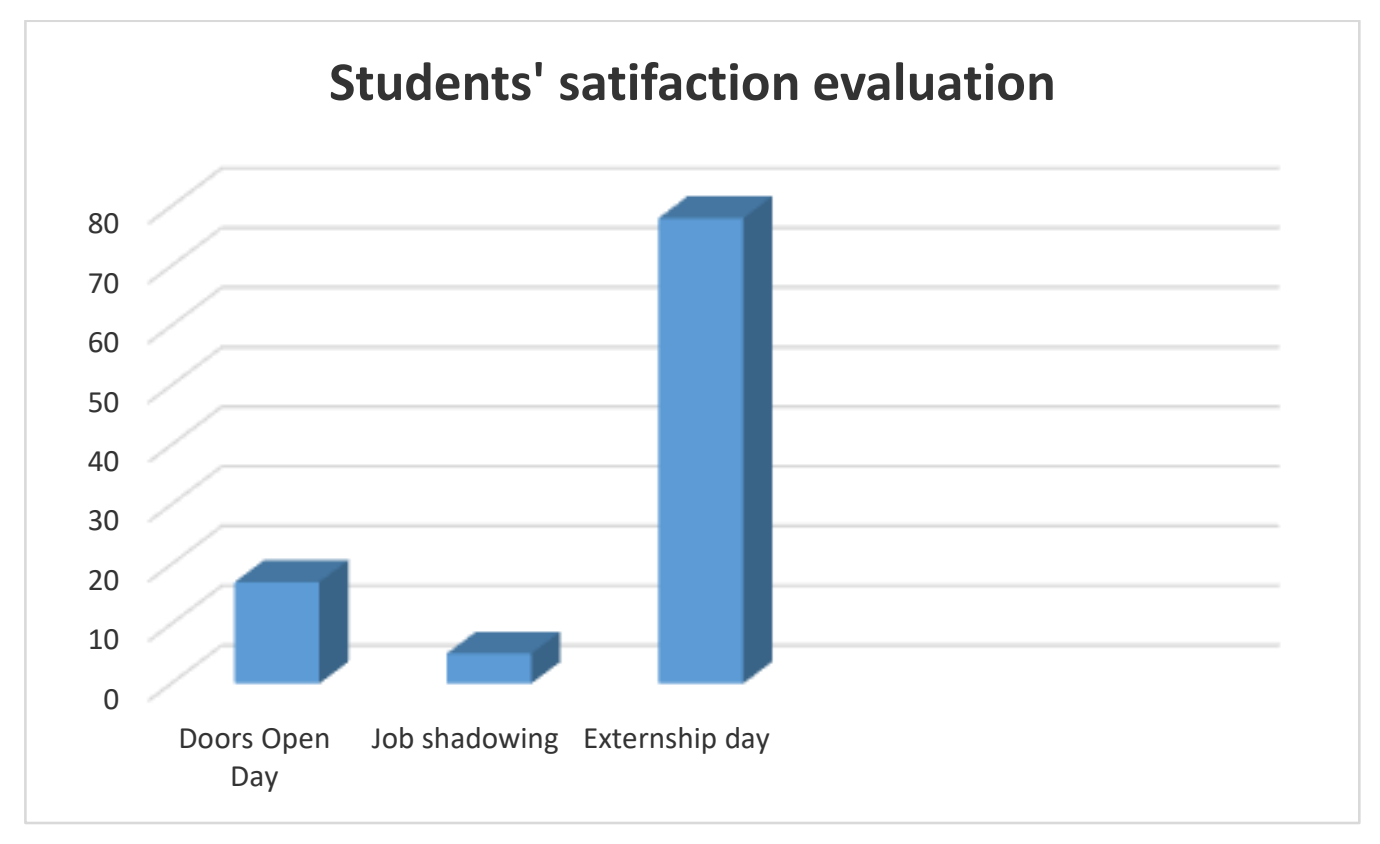

\section{CONCLUSION}

Considering the current situation analysis, conducted research and the existing needs, we can conclude that in Georgia there is a need for establishing the systematic vision of professional orientation and career planning and, therefore, the need to elaborate and implement the necessary mechanisms. As a result of the challenges and observations in Georgia, the activities carried out for the formation of a professor and career planning service has been fragmented and unsystematic. It is necessary to establish a sustainable system of 
professionalism and career planning, which will ensure coordination of general education institutions and economic, business and private sectors, which will be an essential basis for the implementation of professional orientation service. Professional consultation provided by qualified professional consultants will help pupils in making informed choices of future professions.

As the results of the survey have shown, it is important to prepare students prior to their visits to companies, to increase their awareness on the features and characteristics of the profiling enterprise and give them information about the companies' activities, which will be unconditionally useful for practical teaching and job testing.

Finally, it may be concluded that the German government-funded project "Vocational Education and Training Partnership in the South Caucasus" in the framework of the project "the school as a place of learning a profession" with its functionality and capacity is essential in the process of formation of students' sense of citizenship, self-esteem, personality and making of an informed choice.. The project aims at formation and development of the sector of professional orientation and career planning in the pilot region of Gori. The project will facilitate the harmonization of Georgian vocational education and European system.

\section{REFERENCE LIST}

Füsun Akkök, 2015. Handbook for Career Guidance. Technical Assistance to VET and Employment Reforms in Georgia EUVEGE

Ch. Schiermann, B.Ertelt, J. Katsarov, R. Mulvey, H. Reid and P. Weber. 2014. NICE HandbookNICE Handbook for the Academic Training of Career Guidance and Counselling Professionals. HdBA

Matching Skills and Labour Market Needs Building Social Partnerships for Better Skills and Better Jobs. 2014. World Economic Forum Global Agenda Council on Employment

CAREER GUIDANCE IN EDUCATION, PROFESSION AND LABOUR MARKET MANAGEMENT. 2013. Slovak University of Technology in Bratislava

Career Guidance A HANDBOOK FOR POLICY MAKERS. 2004. Organisation for Economic Co-operation and Development (OECD) European Commission (EC)

TORINO PROCESS 2014 GEORGIA

Sectorial Policy Support Program: Employment and Vocational Education and Training 